\title{
Ensaio sobre os saberes docentes do bacharel professor de instrumento
}

\author{
Vanessa Weber \\ Luciane W. F. Garbosa \\ (UFSM)
}

Resumo: Neste ensaio, nos propomos a refletir sobre os saberes docentes específicos ao bacharel que atua como professor de instrumento. Apesar das mudanças que vêm ocorrendo nas matrizes curriculares de muitas instituições, a formação do bacharel ainda é voltada essencialmente para a performance, mesmo que, na maioria das vezes, este atue como professor de instrumento. Tal conflito entre formação e atuação torna essencial a compreensão de quais são, e como são mobilizados, os conhecimentos necessários ao bacharel professor. Neste sentido, tendo como fundamento estudos de Tardif (2012), Gauthier et al. (2006), Bolzan (2002) Bolzan e Isaia (2006) e Isaia e Bolzan $(2009,2010)$, trazemos algumas reflexões em torno dos saberes do professor de instrumento. Para tanto, realizamos um levantamento nas pesquisas cujo foco recai no bacharel que atua como professor de instrumento. Verificamos muitos pontos comuns nos estudos produzidos sobre a temática, particularmente no que tange às dificuldades que os bacharéis experimentam, considerando as lacunas na formação pedagógica, e a necessidade de repensar o currículo dos bacharelados em instrumento, de modo que ofereçam um preparo para esta especificidade do mercado de trabalho.

Palavras-chave: saberes docentes, professor de instrumento, docente-bacharel

\section{ESSAY ON THE TEACHING KNOWLEDGE OF THE BACHELOR-INSTRUMENT TEACHER}

Abstract: We discuss the specific teaching knowledge of the bachelor in performance. The bachelor's education focus on performance, but they usually teach their instrument. Such conflict between education and professional life makes essencial the understanding of the knowledge necessary for the bachelor-teacher. We reflect, using theories from Tardif (2012) e Gauthier et al. (2006), on the teaching knowledge of the bachelor who teaches instrument. We survey research on such bachelor, and concluded that there are many points in common, particularly the difficulties bachelors face when teaching due to the gap in their education, and the need to rethink the curriculum for baccalaureate in instrument so it offers preparation for the market.

Keywords: teaching knowledge, instrument teacher, bachelor-teacher. 


\section{Introdução}

"Todo instrumentista musical é potencialmente um professor de instrumento." (Glaser e Fonterrada, 2007)

A afirmação que abre este artigo costuma fazer parte daquilo que nomeamos como senso comum. A razão deste pensamento se encontra na própria atuação profissional dos instrumentistas formados em cursos de bacharelado, cujo foco recai na formação do intérprete, do músico executante, o qual irá atuar em performances solo, em orquestras ou em conjuntos de câmara, mas que, com muita frequência, atuará como professor de seu instrumento, seja em aulas particulares, em escolas de música especializadas ou mesmo no ensino superior. Esse conflito, entre formação e atuação docente, torna-se relevante quando buscamos compreender os conhecimentos envolvidos e articulados na profissão de professor de instrumento. Um passo importante é o de tentarmos compreender quais são e como se constituem os saberes docentes construídos pelos bacharéis em instrumento na prática pedagógica.

Assim, trazemos alguns questionamentos que podem auxiliar nesta discussão: Como o bacharel torna-se professor de instrumento? Qual a formação que o bacharel recebe para a profissão docente? Quais os saberes que este professor mobiliza nas aulas de instrumento? Quais as fontes desses saberes? Como o bacharel em instrumento constrói seus saberes docentes? Refletimos sobre estas questões tendo como base estudos de Tardif (2012), Gauthier et al. (2006), Bolzan (2002) Bolzan e Isaia (2006) e Isaia e Bolzan (2009, 2010), além de destacar pesquisas que investigaram tanto a formação quanto os saberes mobilizados na docência do instrumento.

Ao fazermos referência à formação para a docência, partimos do pressuposto de que esta ocorre ao longo de toda a vida do professor, o qual está continuamente aprendendo os saberes necessários à prática pedagógica (Tardif, 2012). Deste modo, a aprendizagem relacionada ao que é ser professor e os processos formativos inicia-se antes mesmo da formação para a docência, ocorrendo na infância junto à família e no momento da escolarização, período em 
que se vivencia a escola como aprendiz. Tardif (2012) aponta que "de fato, as experiências formadoras vividas na família e na escola se dão antes mesmo que a pessoa tenha desenvolvido um aparelho cognitivo aprimorado para nomear e indicar o que ela retém dessas experiências" (p. 67), o que indica que as experiências que o professor vivenciou durante sua infância e como aluno, antes mesmo de decidir pela carreira docente, influenciam sua forma de agir na docência.

Nos primeiros anos como professor, nos referenciamos às imagens, às posturas pessoais e profissionais, às performances de professores que ficaram nas nossas lembranças. Portanto, nossos processos formativos não se iniciam num curso intencionalmente escolhido (ou não), mas nos espaços e tempos distintos onde já vivemos a experiência discente. Estes processos são contínuos, mesmo que não sejam percebidos e nem refletidos. (Oliveira, 2006).

Neste sentido, o ingresso na graduação não pode ser considerado como a fase inicial ou única do aprender docente, visto que "os processos de aprender a ensinar e de aprender a ser professor são lentos, pois se iniciam antes do espaço formativo dos cursos de licenciatura e se prolongam por toda a vida profissional" (Mizukami, 2008, p. 389). Compreendemos que a aprendizagem docente para o bacharel que atua com o ensino de instrumento também se inicia antes do ingresso na graduação, de modo que, as experiências que o bacharel vivenciou como aluno de instrumento contribuem para a aprendizagem docente. Assim, a observação de como o antigo professor trabalhava, organizava as aulas, ensinava determinados aspectos da técnica instrumental ou do repertório, assim como as demais vivências como aluno de instrumento, fazem parte da formação para a docência do bacharel que atua como professor, assim como contribuem para a construção dos saberes mobilizados por este professor. 


\section{Saberes docentes no contexto do professor de instrumento}

As pesquisas brasileiras sobre formação de professores e aprendizagem docente passaram a ter o professor como elemento central, sobretudo a partir da década de 1990. Neste momento surgia também o interesse sobre os saberes docentes, os quais apareceram vinculados às pesquisas relacionadas ao trabalho do professor e à própria construção da docência. Nunes (2001) afirma que na “perspectiva de analisar a formação de professores, a partir da valorização destes, é que os estudos sobre os saberes docentes [ganharam] impulso e [começaram] a aparecer na literatura, numa busca de se identificarem os diferentes saberes implícitos na prática docente" (p. 29).

Para Gauthier et al. (2006), o ponto central das pesquisas e reflexões sobre a formação e a profissão docente consiste na caracterização da "natureza dos saberes subjacentes ao ato de ensinar, isto é, o conjunto de conhecimentos, competências e habilidades que servem de alicerce à prática concreta do magistério e que poderão, eventualmente, ser incorporados aos programas de formação de professores" (p. 14). Pensando-se no bacharel que atua com a docência do instrumento, a pesquisa sobre seus saberes docentes, além de caracterizar os conhecimentos, competências e habilidades específicas deste professor, poderia contribuir para a reflexão sobre os currículos dos cursos de bacharelado, os quais, na maioria das vezes não contemplam disciplinas pedagógicas em sua matriz curricular.

Os autores apontam ainda que o ensino é uma profissão exercida em praticamente todo o mundo, desde a Antiguidade. No entanto, os fenômenos específicos ao processo são pouco conhecidos, tendo em vista que os atos que realmente influenciam na aprendizagem dos alunos ainda não foram totalmente identificados, não se compreendendo plenamente como se dá a interação entre professores e alunos. Nesse sentido, o estudo sobre estes pontos e sobre os "elementos do saber profissional docente é fundamental e pode permitir que os professores exerçam o seu ofício com muito mais competência" (Gauthier et al., 2006, p. 17). 
Ao refletir sobre os saberes docentes dos professores de instrumento, torna-se importante o conhecimento e a definição deste saber. Para isso, adotamos a perspectiva de Tardif (2012) que, apesar de salientar a dificuldade de se produzir um conceito que venha a satisfazer todos os pesquisadores, visto que cientificamente ninguém sabe com certeza o que é um saber, propõe uma definição atribuindo “à noção de 'saber' um sentido amplo que engloba os conhecimentos, as competências, as habilidades (ou aptidões) e as atitudes dos docentes, ou seja, aquilo que foi muitas vezes chamado de saber, de saber-fazer e de saber-ser" (Tardif, 2012, p. 60). Os termos saber e saber fazer também são abordados por Bolzan e Isaia (2006), autoras que relacionam o saber ao conhecimento científico e o saber fazer ao conhecimento prático.

Além de contribuírem para que o professor atue com mais competência, como apontado por Gauthier et al. (2006), os estudos acerca dos saberes docentes são importantes, considerando a conquista da profissionalização da docência. Nesta perspectiva, Tardif (2012) afirma que a natureza dos conhecimentos envolvidos é o que distingue as profissões das demais ocupações e considera o ensino como um ofício, o qual seria exercido por vocação, por amor, e não como uma verdadeira profissão, compreendida como as profissões de médico, engenheiro ou advogado. Da mesma forma, Gauthier et al. (2006) também não consideram a docência como uma profissão e, em uma escala de cinco níveis de profissionalização (profissões marginais, ocupações que aspiram à profissionalização, semiprofissões, novas profissões e profissões tradicionalmente estabelecidas), a categoria dos professores representaria uma semiprofissão.

Destacamos ainda, que "em educação, a profissionalização pode ser definida, em grande parte, como uma tentativa de reformular ou renovar os fundamentos epistemológicos do ofício de professor e de educador, assim como da formação para o magistério" (Tardif, 2012, p. 250). Neste sentido, diversas pesquisas ${ }^{1}$, que apontam diferentes enfoques para a profissionalização docente, enfatizam a importância do saber neste processo, sendo que a posse de um saber específico representa uma das dimensões essenciais das profissões. Gauthier et al.

\footnotetext{
${ }^{1}$ Pesquisas abordadas por Gauthier et al. (2006).
} 
(2006) apontam que "a identificação e a validação de um repertório de conhecimentos específicos ao ensino contribuiria, com certeza, para definir o status profissional dos professores" (p. 77-78). A contribuição para a profissionalização da docência, apontada por Gauthier et al. (2006) e Tardif (2012), é relevante também para a área da música e do professor de instrumento. É recorrente em nossa área a percepção de que todo instrumentista pode ser professor de seu instrumento. Esta ideia, porém, vem a desqualificar este profissional, o qual necessita de saberes para além dos conhecimentos técnico e musical no instrumento para atuar como professor.

Para refletir sobre os saberes mobilizados por professores de instrumento nos baseamos em Gauthier et al. (2006) e Tardif (2012), autores que se tornaram referências para o estudo dos saberes docentes. Citado de forma recorrente nas pesquisas sobre o professor de instrumento, Tardif (2012) assinala que a compreensão dos saberes docentes pode ocorrer mais facilmente por meio de um modelo de análise que esteja baseado na origem social destes saberes. Neste sentido, o autor aponta que

[...] o saber dos professores contém conhecimentos e um saber-fazer cuja origem social é patente. Por exemplo, alguns deles provêm da família do professor, da escola que o formou e de sua cultura pessoal; outros vêm das universidades ou das escolas normais; outros estão ligados à instituição (programas, regras, princípios pedagógicos, objetivos, finalidades, etc.); outros, ainda, provêm dos pares, dos cursos de reciclagem etc. Nesse sentido, o saber profissional está, de um certo modo, na confluência de vários saberes oriundos da sociedade, da instituição escolar, dos outros atores educacionais, das universidades, etc. (Tardif, 2012, p. 19).

Além de sociais, os saberes docentes são caracterizados pelo autor como saberes temporais, visto que são construídos ao longo da história de vida e carreira docente. São saberes adquiridos enquanto o professor ainda vivenciava o papel de aluno, em paralelo à construção de crenças e representações sobre o que é ser professor. Assim, "dizer que o saber dos professores é temporal significa dizer, inicialmente, que ensinar supõe aprender a ensinar, ou seja, aprender a dominar progressivamente os saberes necessários à realização do trabalho docente" (Tardif, 2012, p. 20). 
Outro ponto a destacar é o fato de que para o autor o estudo sobre os saberes docentes deve estar ligado ao estudo das demais dimensões do ensino e, principalmente, ao estudo do trabalho realizado diariamente pelos professores. Segundo Tardif (2012), não se pode estudar os saberes docentes sem relacioná-los a estas dimensões, ao contexto de trabalho e da vida dos professores.

O saber dos professores é o saber deles e está relacionado com a pessoa e a identidade deles, com a sua experiência de vida e com a sua história profissional, com as suas relações com os alunos em sala de aula e com os outros atores escolares na escola, etc. Por isso, é necessário estudá-lo relacionando-o com esses elementos constitutivos do trabalho docente. (Tardif, 2012, p. 11).

Com relação à definição e categorização dos saberes docentes, Tardif (2012) afirma que o saber dos professores é um saber plural, formado por um conjunto de conhecimentos provenientes da formação profissional e de saberes disciplinares, curriculares e experienciais.

Os saberes da formação profissional englobam os saberes das ciências da educação e da ideologia pedagógica e são saberes adquiridos pelos professores nas instituições de formação. Os saberes disciplinares também são adquiridos ao longo da formação e representam os diversos campos do conhecimento, ou seja, são os saberes que se encontram nas universidades sob a forma de disciplinas, como por exemplo, matemática, física e história. Os saberes curriculares representam os programas escolares, ou seja, os objetivos, conteúdos e métodos que as instituições escolares organizam e "que os professores devem aprender a aplicar" (Tardif, 2012, p. 38). Por fim, os saberes experienciais são saberes desenvolvidos pelos professores durante sua prática docente. O autor aponta que o "o professor ideal é alguém que deve conhecer sua matéria, sua disciplina e seu programa, além de possuir certos conhecimentos relativos às ciências da educação e à pedagogia e desenvolver um saber prático baseado em sua experiência cotidiana com os alunos" (Tardif, 2012, p. 39). Neste ponto, questionamos sobre esse "professor ideal". Será que existe um professor ideal? Considerando o professor de instrumento, podemos pensar em um professor ideal? Ao sermos prescritivos, corremos o risco de sermos parciais definindo como deve agir e ser o 
"professor ideal". No entanto, é possível, dentre as múltiplas possibilidades e experiências, apontar caminhos para que cada professor, ao refletir sobre sua prática, se torne um professor melhor para determinado grupo de estudantes, levando em consideração suas vivências e seu contexto de trabalho.

Além dos saberes definidos por Tardif (2012), Gauthier et al. (2006) acrescentam às categorias o saber da ação pedagógica, caracterizado como "o saber experiencial dos professores a partir do momento em que ele se torna público e é testado através de pesquisas em sala de aula" (Gauthier et al., 2006, p. 33). A importância do estudo do saber da ação pedagógica, é apontada por Puentes et al. (2009), quando afirmam que

[...] a contribuição mais importante de Gauthier et al. (1998) está, precisamente, no alongamento do campo teórico desse último saber, ou seja, o da ação pedagógica, até o momento, considerado como o menos desenvolvido no reservatório de saberes do professor e, também, contraditoriamente, o mais necessário à profissionalização do ensino. (Puentes, et al., 2009, p. 176).

Referindo-se aos saberes docentes, Gauthier et al. (2006) assinalam que normalmente utiliza-se a expressão knowledge base, considerada como uma espécie de reservatório de conhecimentos, englobando a totalidade dos saberes dos professores, ou seja, "conhecimento do conteúdo, saber experiencial, conhecimento das crianças, conhecimento do programa, conhecimento relativo ao gerenciamento da classe, conhecimento de si mesmo, cultura geral, etc." (p. 18). Em seus estudos, entretanto, para se referir aos saberes docentes, os autores utilizam a expressão repertório de conhecimentos, o qual "representa um subconjunto do reservatório geral de conhecimentos do professor e tem origem nas pesquisas realizadas nas salas de aula" (Gauthier et al., 2006, p. 18).

Com relação à categorização, Gauthier et al. (2006) apresentam seis tipos de saberes que compõem o repertório de conhecimentos necessários ao professor, sendo eles: 1) Saberes disciplinares; 2) Saberes curriculares; 3) Saberes das ciências da educação; 4) Saberes da tradição pedagógica; 5) Saberes experienciais; e 6) Saberes da ação pedagógica. 
Segundo Gauthier et al. (2006), os saberes disciplinares são saberes produzidos pelos cientistas e pesquisadores das diversas disciplinas científicas. "O professor não produz o saber disciplinar, mas, para ensinar, extrai o saber produzido por esses pesquisadores" (p. 29). No contexto do Curso de Bacharelado em Instrumento, apesar de grande parte das disciplinas do currículo não tratarem das questões pedagógicas de modo aprofundado, contribuem para a construção da docência do bacharel. Neste sentido, história da música, análise, harmonia, teoria musical, dentre outras, são relevantes para o bacharel enquanto professor, visto que essas disciplinas são essenciais para a construção dos saberes disciplinares, mais tarde mobilizados nas aulas. Em muitos casos, o aluno do curso de bacharelado e futuro professor de seu instrumento pode não perceber a importância destas disciplinas para a docência enquanto as cursa. Porém, no momento da prática pedagógica estes saberes se mostram necessários. Os conhecimentos construídos nas disciplinas teóricas, por exemplo, são mobilizados quando o professor precisa articular a forma e interpretação das obras musicais, tanto para si quanto para os alunos. Da mesma forma, através desses saberes, o professor compreende as relações entre os elementos de uma composição e sua dimensão expressiva. Estas relações, por sua vez, influem em suas decisões interpretativas e incitam o aluno a refletir sobre o processo de construção da performance musical. Os conhecimentos desenvolvidos nas disciplinas de história da música também são utilizados em aulas de instrumento, pois a compreensão estilística e das características de um determinado período, influem em outros aspectos de execução, fraseado, dinâmicas e articulação. Sobretudo, é essencial que o professor seja capaz de contextualizar musical e historicamente a obra estudada para tornar a aprendizagem mais significativa.

Os saberes curriculares são saberes que o professor utiliza para ensinar determinada disciplina. Para transformar uma disciplina em programa de ensino, as instituições escolares organizam os saberes produzidos pelas ciências que consideram relevantes, e os transformam em métodos, objetivos e programas de ensino. "O professor deve, evidentemente, 'conhecer o programa', que constitui um outro saber de seu reservatório de conhecimentos. É, de fato, o programa que Ihe serve de guia para planejar, para avaliar" (Gauthier et al., 2006, p. 31). No 
contexto do professor de instrumento, compreendemos os saberes curriculares como

[...] um conjunto de conhecimentos [do professor de instrumento], frequentemente relacionados ao conhecimento de um programa de ensino, no qual ele passa a dominar um elenco de conteúdos que possibilitam o planejamento e avaliação de suas atividades, de forma sistematizada, progressiva, contemplando diferentes possibilidades metodológicas e de repertório. (Araújo, 2006, p. 60).

Assim, a depender do contexto de trabalho, os professores constroem estes saberes curriculares, relativos aos programas, métodos e repertórios organizados pelas instituições de ensino e mobilizados pelos professores durante as aulas de instrumento. Para refletir sobre a mobilização do saber curricular no contexto do professor de instrumento, trazemos o trabalho em Conservatórios e contextos que utilizam métodos específicos de ensino de instrumento. Com relação aos Conservatórios de Música, geralmente tais contextos possuem um programa de ensino, o qual inclui peças determinadas para o repertório a ser desenvolvido com os alunos, além de metas com relação à técnica e ao desenvolvimento instrumental do aluno. Percebemos também a mobilização de saberes curriculares pelos professores de instrumento que organizam sua prática com base em um método específico de ensino de instrumento, como por exemplo, o Método Suzuki. Assim como as instituições escolares organizam os conhecimentos científicos em programas de ensino, o Método Suzuki organiza os conhecimentos musicais e o repertório trabalhado em uma série de Livros. Neste sentido, professores que trabalham com esse método conhecem este "programa", mobilizando conhecimentos a respeito dos livros de repertório e da sequência e maneira com que os conteúdos musicais são trabalhados com os alunos do Método. Compreendemos que estes saberes mobilizados tanto por professores de Conservatórios quanto por professores que atuam a partir de um método específico são exemplos vinculados ao que Gauthier et al. (2006) e Tardif (2012) apontam como o saber curricular.

Os saberes das ciências da educação são saberes profissionais adquiridos pelo professor durante sua formação e em seu trabalho, os quais não se 
encontram, porém, diretamente relacionados à prática pedagógica. Estes saberes, no entanto, orientam o professor sobre sua profissão e de modo geral, sobre a educação. Segundo Gauthier et al. (2006) "o professor possui noções relativas ao sistema escolar sabe o que é um conselho escolar, um sindicato, uma carga horária" (p. 31), ou seja, é um conjunto de saberes que o professor possui "a respeito da escola que é desconhecido pela maioria dos cidadãos comuns e pelos membros das outras profissões" (Gauthier et al., 2006, p. 31). Segundo os autores, esse é um saber profissional específico "que serve de pano de fundo tanto para ele quanto para os outros membros de sua categoria socializados da mesma maneira. Esse tipo de saber permeia a maneira de o professor existir profissionalmente" (p. 31). Esta categoria de saberes está relacionada, sobretudo, aos professores que atuam em escolas de educação básica e que tiveram sua formação em cursos de licenciatura, dificilmente fazendo parte dos saberes dos bacharéis que atuam com a docência do instrumento. Percebemos que no contexto destes professores este saber não foi construído durante a graduação, mas pode se fazer presente em suas práticas pedagógicas. Dependendo do contexto de trabalho do professor de instrumento, conhecimentos a respeito deste contexto fazem parte da formação deste docente. Neste sentido, podemos considerar que o conhecimento sobre a organização de um conservatório, sobre a estrutura de um projeto social e sobre a gestão de uma escola de música se aproximam ao saber que o professor da escola de educação básica possui.

Os saberes da tradição pedagógica referem-se à ideia do que é uma aula, a qual é constituída antes mesmo da formação para a profissão docente. Segundo Gauthier et al. (2006), “cada um tem uma representação da escola que o determina antes mesmo de ter feito um curso de formação de professores, na universidade" (p. 32). Este é um saber que pode apresentar erros, mas que poderá ser ajustado pelo saber experiencial e validado ou não pelo saber da ação pedagógica. Compreendemos que a aprendizagem da docência do bacharel em instrumento, assim como de professores de outras áreas, é influenciada pelas experiências vivenciadas enquanto aluno, as quais contribuem para a construção dos saberes da tradição pedagógica. Segundo Tardif (2012) 
[...] antes mesmo de ensinarem, os futuros professores vivem nas salas de aula e nas escolas - e, portanto, em seu futuro local de trabalho - durante aproximadamente 16 anos (ou seja, em torno de 15.000 horas). Ora, tal imersão é necessariamente formadora, pois leva os futuros professores a adquirirem crenças, representações e certezas sobre a prática do ofício de professor, bem como sobre o que é ser aluno. Em suma, antes mesmo de começarem a ensinar oficialmente, os professores já sabem, de muitas maneiras, o que é o ensino por causa de toda a sua história escolar anterior. (Tardif, 2012, p. 20).

Assim, ao se tornar professor, o bacharel carrega consigo uma extensa "bagagem" de conhecimentos, modelos de professores e metodologias experienciadas durante o processo de formação, as quais se tornam referências no momento da atuação docente. Os modelos dos antigos professores constituem-se em referências de como dar aulas, como conduzir e organizar a prática docente, o que compreendemos como equivalente ao saber da tradição pedagógica (Gauthier et al., 2006). Conforme discutido, o bacharel em instrumento não tem sua formação voltada à docência, mas, em virtude de suas experiências como aluno, guarda consigo a representação do que é o ensino e de como podem e devem ser as aulas de instrumento, saber esse construído, sobretudo, a partir dos modelos dos antigos professores e das aprendizagens ao longo do processo formativo.

Os saberes experienciais são produzidos pelos professores de modo particular e único por meio das vivências como docente em sala de aula. Através de suas experiências, o professor vai criando hábitos e regras que utiliza em sua prática e, assim, aprende o que funciona ou não no ensino. A aprendizagem da docência, adquirida por meio dos processos formativos em espaços formais, não formais e informais, da qualidade das experiências docentes e do tempo de prática pedagógica é importante, reconhecida e valorizada pelos professores. No entanto, segundo Gauthier (et al., 2006) "a maioria deles afirma ter aprendido a ensinar pela própria experiência, ao sabor dos erros e acertos" (p. 24).

Com relação aos bacharéis, professores de instrumento, a experiência também é considerada como importante elemento para a aprendizagem docente e construção de saberes. De modo geral, as aprendizagens construídas através da experiência são similares para estes professores (Weber, 2014). Tranquilidade e segurança na docência, além do fato de aprender a lidar com as particularidades 
de cada aluno são aspectos adquiridos com o passar do tempo e com as experiências pedagógicas. Além disso, os professores de instrumento constroem saberes experienciais relacionas ao seu contexto de trabalho e às dificuldades enfrentadas na prática. Neste sentido, o contato com metodologias com as quais não estão habituados a trabalhar, alunos com dificuldades de aprendizagem, relacionamento com pais dos alunos, falta de reconhecimento e motivação por parte dos alunos, etc., são alguns dos desafios a serem enfrentados. As dificuldades se constituem em momentos de aprendizagem docente para o bacharel em instrumento, de modo que estes professores, refletindo sobre sua prática e buscando soluções para suas dificuldades, constroem saberes experienciais. Segundo Gauthier et al. (2006), a limitação deste tipo de saber é o fato dele não ser verificado cientificamente, constituindo-se em um saber que permanece reduzido à sala de aula de cada professor.

A partir dessa limitação, Gauthier et al. (2006) apontam outro saber docente, o saber da ação pedagógica. Como mencionado, o saber do professor permanece muitas vezes reduzido à escola, não passando por análise científica, o que também acontece no contexto do professor de instrumento. O saber da ação pedagógica representa o saber experiencial do professor, seus julgamentos, suas "regras", a partir do momento em que são analisados e testados por meio de pesquisas realizadas em sala de aula. Com esse saber, as regras de ação dos professores pesquisados poderão ser conhecidas, aprendidas e utilizadas por outros professores. Assim, o saber da ação pedagógica passa a contribuir com o aperfeiçoamento da prática docente. Durante a prática pedagógica, os professores de instrumento buscam por pesquisas e referências, sobretudo em momentos de dificuldades e diante de situações que não sabem como resolver (Weber, 2014). Assim, o saber da ação pedagógica é mobilizado pelos professores de instrumento em suas práticas, relacionando-se às situações que vivenciam em seu trabalho e às dificuldades que encontram na prática pedagógica.

Os saberes docentes apontados por Gauthier et al. (2006) e Tardif (2012), dentre os quais incluem-se os saberes disciplinares, curriculares, das ciências da educação, da tradição pedagógica, experienciais e da ação pedagógica, são saberes mobilizados por professores de todas as áreas do conhecimento. No 
entanto, pensando especificamente na área de música e nos bacharéis, professores de instrumento, surgem algumas ideias, uma vez que a formação no bacharelado é voltada, sobretudo, à performance musical.

A performance musical que o bacharel aprende durante a graduação diz respeito ao sentido mais restrito de performance definido por Sloboda (1985), que envolve um músico, ou grupo de músicos, executando para uma audiência obras musicais previamente compostas. Esta acepção é tomada como base para as reflexões deste artigo. Neste âmbito, o ofício do bacharel em instrumento corresponde ao do performer. ${ }^{2}$ Clarke (2002) explica que o requisito para a atuação do performer envolve, principalmente, a capacidade de produzir, de forma expressiva, as notas, ritmos, dinâmicas, etc., de uma composição musical, de forma a trazê-la à vida. Tal capacidade envolve conhecimentos que vão além da notação musical, abarcando concepções estilísticas e históricas relacionadas às obras executadas, além de um preparo físico e psicológico para enfrentar o estresse típico de uma situação de palco.

Os conhecimentos descritos por Sloboda (1985) e Clarke (2002) envolvendo a técnica, expressão musical e a apresentação pública são alguns dos principais aspectos trabalhados nas aulas de instrumento. Assim, como o professor aborda com o aluno as questões relativas à performance musical? Como o professor de instrumento prepara o aluno para subir ao palco e tocar para dezenas (ou mais) de pessoas? Que tipo de saber é mobilizado para essas situações? Como se definem os saberes específicos do professor de instrumento?

Ao longo de sua formação, o bacharel em instrumento constrói conhecimentos específicos sobre a técnica do instrumento, repertório, performance, etc., principalmente nas disciplinas de instrumento e recitais. Consideramos este conjunto de conhecimentos como o saber da performance, o qual inclui aspectos relacionados à técnica, expressão musical, comunicação para uma audiência, postura, além do preparo físico e emocional para a apresentação pública. Neste sentido, tal saber é importante para o professor de instrumento porque lida diretamente com o objeto de aprendizagem das aulas de instrumento,

2 No contexto musical, performer é o termo em inglês para o músico executante, ou intérprete. 
ou seja, a performance musical. O constante contato com questões musicais e com a reflexão sobre como desenvolver determinados aspectos técnicos e expressivos, proporcionado pela performance musical, contribui para o ensino do instrumento. Além disso, o professor, enquanto performer, oferece um modelo ao aluno, o qual pode proporcionar motivação para o estudo, assim como tranquilidade no momento em que o aluno estiver diante de uma situação de performance pública.

Além do saber da performance, outros conhecimentos específicos ao professor de instrumento podem ser mencionados, como os saberes da função educativa (Araújo, 2006). Segundo a autora, tais saberes também são específicos ao professor de instrumento, visto que "se referem especificamente às práticas de viabilização do ensino do instrumento, como a didática, as metodologias empregadas, enfim, ao conjunto de conhecimentos que fazem parte do 'ser' professor de [instrumento] no que tange a sua função de ensino" (Araújo, 2006. p. 61). Estes saberes são construídos por meio de fontes sociais e disciplinas voltadas à pedagogia do instrumento. Salientamos que além das fontes sociais e das disciplinas específicas, estes saberes podem ser construídos em cursos de pedagogia do instrumento, fora do contexto universitário, como por exemplo, nos cursos de capacitação para professores do Método Suzuki.

\section{O docente-bacharel e as pesquisas em torno dos saberes do professor de instrumento}

Ao buscarmos por pesquisas que investigaram os bacharéis que atuam como docentes de seus instrumentos encontramos várias denominações para esse professor, dentre as quais:

a) Instrumentista-professor (Glaser; Fonterrada, 2007): ao utilizar este termo, as autoras referem-se ao músico instrumentista que teve sua formação no curso de Bacharelado, direcionada, exclusivamente, para a execução musical, porém que atua como docente de seu instrumento.

b) Músico-professor (Requião, 2002): diz respeito a, 
[...] aquele que teve uma formação profissional voltada para o desenvolvimento de atividades artísticas na área da música, e que coloca a atividade docente em segundo plano no escopo de suas atividades profissionais, apesar dessa ser, frequentemente, a atividade mais constante e com uma remuneração mais regular em seu cotidiano profissional. Sua atuação como docente se dá prioritariamente no âmbito de escolas de música alternativas e em aulas particulares, onde desenvolve um trabalho, em especial, através da música popular brasileira. (Requião, 2002, p. 64).

c) Docente/bacharel (Araújo, 2005): para a autora, o termo refere-se ao profissional que teve sua formação em um curso de bacharelado, o qual privilegia a performance como profissão, mas atua com a docência do instrumento.

d) Docente-bacharel (Weber, 2014): Embora apresente terminologia semelhante ao sugerido por Araújo (2005), o termo diz respeito ao profissional formado em curso de bacharelado, o qual atua com a performance, mas privilegia a docência como atividade profissional.

Considerando que buscamos refletir sobre os saberes docentes necessários à atuação dos docentes-bacharéis, a formação desses professores torna-se foco de nossa atenção. Neste sentido, de modo geral, os bacharéis não possuem formação didática e pedagógica voltada para a docência. "Tal ocorrência deve-se pela ausência de disciplinas que contemplem a metodologia de ensino em sua matriz curricular e, assim, permitam a construção de competências profissionais necessárias à prática docente" (Ramos et al., 2010, p. 2). Os cursos de bacharelado proporcionam aos alunos uma formação que se destina à atuação em espaços diversos, os quais, de forma geral, não incluem o ambiente escolar, ou seja, uma formação que não é voltada para a docência. "Seu programa de ensino segue diretrizes próprias a cada curso, norteado por conteúdos 'técnicos' que atendem às necessidades do campo de trabalho específico" (Ramos et al., 2010. p. 5).

Mesmo não tendo uma formação específica para a docência, encontramos muitos bacharéis atuando como professores, com destaque para as universidades, pois para o exercício da docência nesta instituição nem sempre é exigida formação em cursos de licenciatura. As exigências para a docência no ensino superior são estabelecidas pelo artigo 66 da Lei de Diretrizes e Bases da Educação Nacional. 
Art. 66. A preparação para o exercício do magistério superior far-se-á em nível de pós-graduação, prioritariamente em programas de mestrado e doutorado.

Parágrafo único. O notório saber, reconhecido por universidade com curso de doutorado em área afim, poderá suprir a exigência de título acadêmico. (BRASIL, 1996).

Com relação aos bacharéis formados em Cursos de Música, a situação não é diferente. Glaser e Fonterrada (2007) assinalam que mesmo sendo formado em um curso de bacharelado, o professor de instrumento é o músico instrumentista. “Ser instrumentista-professor é uma peculiaridade presente na prática profissional do músico em diferentes países, confirmando que, embora tocar e lecionar sejam atividades completamente diferentes, elas são habitualmente exercidas pelo mesmo profissional" (Glaser; Fonterrada, 2007, p.34).

Esta especificidade do docente-bacharel em instrumento provém do pensamento de que ao saber tocar um instrumento musical, o músico está apto a ensiná-lo. Esta ideia, porém, não condiz com a realidade, pois saber tocar não garante o saber ensinar, principalmente considerando-se que este professor não possui formação pedagógica ou didática.

Basta conhecer o conteúdo. Pensou-se, durante muito tempo, e muitos, sem dúvida, ainda pensam assim, que ensinar consiste apenas em transmitir um conteúdo a um grupo de alunos. [...] Mas quem ensina sabe muito bem que, para ensinar, é preciso muito mais do que simplesmente conhecer a matéria, mesmo que esse conhecimento seja fundamental. Quem ensina sabe que deve também planejar, organizar, avaliar, que também não pode esquecer os problemas de disciplina [...] quem mergulha diariamente nesse ofício sabe muito bem que, apesar da grande importância de se conhecer a matéria, isso não é suficiente por si só. (Gauthier et al., 2006, p. 20).

Assim, percebemos que para ensinar o instrumento não basta saber tocálo, o que, conforme Gauthier et al. (2006), reduziria uma atividade tão complexa a uma única dimensão. O docente-bacharel, de modo geral, sabe tocar seu instrumento, conhece sua técnica e seu repertório, porém somente isso não o qualifica para atuar como docente. Além dos conhecimentos específicos, são 
necessários conhecimentos de outras naturezas, envolvendo os saberes relativos aos processos de ensino e de aprendizagem.

Segundo Gauthier (et al., 2006) as pesquisas sobre os saberes docentes vêm a contribuir com a construção do corpus de saberes profissionais próprios dos professores. Encontramos neste ponto a importância dos estudos sobre os saberes docentes, visto que "uma das condições essenciais a toda profissão é a formalização dos saberes necessários à execução das tarefas que Ihe são próprias" (Gauthier et al., 2006, p.20).

A pesquisa sobre os saberes dos professores de instrumento torna-se então "um passo significativo para a compreensão de sua profissionalidade" (Araújo, 2005, p. 56). Como parte de um levantamento bibliográfico, levantamos algumas pesquisas que buscaram compreender os saberes mobilizados pelos professores de instrumento, contribuindo assim para a construção de um corpus de saberes específicos ao professor de instrumento. Tais pesquisas investigaram: os saberes e competências da atividade docente do músico-professor (Requião, 2002); os saberes docentes do instrumentista professor (Carvalho, 2004); os saberes pedagógicos na docência em música (Bello, 2004); os saberes que norteiam a prática pedagógica de professores de piano (Araújo, 2005); os saberes de professores de piano em início de carreira (Gemesio, 2010); e os saberes docentes dos bacharéis em instrumento que atuam, sobretudo, com a docência fora do ambiente universitário (Weber, 2014).

A pesquisa de Requião (2002) parte da problemática envolvendo a formação que alunos de cursos de música recebem na graduação e a realidade profissional que vivenciam no cotidiano. A autora expõe as diversas possibilidades de atuação destes alunos (professor, regente de coro, instrumentista, cantor, preparador vocal, operador técnico de áudio, produtor e compositor de trilhas musicais) e reflete sobre a formação necessária para a atuação em cada um destes campos. Assim, desenvolve uma pesquisa com o objetivo de reconhecer e compreender os saberes e as competências que os profissionais da música procuram em seu percurso de formação. A pesquisa foi desenvolvida a partir de um estudo de caso em uma escola de música alternativa do Rio de Janeiro. A 
autora percebeu que a formação obtida nos cursos de graduação em música não abarcava todos os aspectos e saberes requeridos por este músico-professor.

[...] percebemos a existência de uma demanda por saberes não presentes em instituições oficiais para o ensino da música, demanda essa que vem sendo absorvida por escolas de música alternativas como a Rio Música. Além da questão do repertório, os estudantes estão buscando por saberes profissionais, que resultem efetivamente em um saber-fazer. (Requião, 2002. p. 64).

Assim, a autora conclui que existe uma lacuna nos conhecimentos oferecidos pelas Instituições de Ensino Superior, os quais não garantem um saberfazer relacionado ao perfil profissional desejado e em consonância com o mercado de trabalho. Os alunos buscam, portanto, as escolas de música alternativas no intuito de suprir esta lacuna, por meio da aprendizagem de repertórios e instrumentos populares.

A pesquisa de Carvalho (2004) teve por objetivo conhecer e discutir como os professores de instrumento, que lecionam para crianças, relatam seu processo de aprendizagem para a docência tendo como referência os eixos: ensinar e avaliar. Com relação aos saberes docentes, a autora se amparou nos estudos de Tardif e Mizukami. Através de entrevistas com dez professores de instrumento, a autora pôde analisar e discutir os dilemas e reflexões apresentados pelos professores a respeito da realidade do processo de ensino-aprendizagem durante as aulas de instrumento para crianças. Segundo a autora, esta pesquisa traz contribuições no âmbito do desenvolvimento docente dos instrumentistas e da ampliação de produção acadêmica, com foco nos docentes de escolas de música.

Bello (2004) investigou os saberes pedagógicos dos professores bacharéis de instrumentos musicais da Fundação Municipal de Artes de Montenegro (Fundarte). Ao longo do trabalho a autora discute aspectos da formação desses professores e suas concepções sobre educação. Assim como na pesquisa de Carvalho (2004), a investigação de Bello (2004) amparou-se nos estudos de Maurice Tardif. No momento de tratar sobre formação, a pesquisadora tomou como referencial os estudos de Maria Isabel da Cunha. Como metodologia, a autora utilizou o estudo de caso e a produção dos dados foi feita através de 
entrevistas semiestruturadas com quatro professores da Fundarte. Em suas conclusões, a autora aponta para o fato de que a faculdade e os cursos de formação de instrumento não consideram a opção do aluno para o magistério e não reconhecem os saberes oriundos das ciências da educação como indispensáveis para a docência. Assim como mencionado por Glaser e Fonterrada (2007), nas conclusões a autora levanta o debate sobre a formação que os professores de instrumento recebem nos cursos de bacharelado e aponta que sua pesquisa pode trazer contribuições para a discussão em torno dos currículos dos cursos de bacharelado em música.

A pesquisa de Araújo (2005) vem a somar e A contribuir com os estudos sobre a formação do professor (bacharel) de instrumento. A investigação está relacionada ao seu contexto profissional. A autora, bacharel em música, enfrentou uma série de dificuldades ao iniciar-se na profissão de professora de piano, pois sua formação, voltada à performance, ofereceu poucas disciplinas orientadoras da prática pedagógica do instrumento. Assim, ao longo da profissão, a professora fundamentou sua prática em saberes adquiridos ao longo da formação profissional e, principalmente, durante a prática da profissão. A pesquisa teve como objetivo investigar os saberes que norteiam a prática pedagógica de professores de piano em diferentes etapas da carreira. A investigação, de caráter qualitativo, foi realizada através da metodologia de estudo multicaso e a produção dos dados se deu por meio de entrevistas semiestruturadas e observações não-participantes. Foram escolhidos como casos para a investigação três professores de piano, os quais, segundo o referencial de Huberman, se encontravam em diferentes etapas da carreira docente: fase inicial (três anos); fase intermediária (19 anos); e fase final (43 anos) ${ }^{3}$. Para a análise dos dados, a autora utilizou como referência os saberes docentes descritos nos trabalhos de Maurice Tardif.

Ao longo da pesquisa, foram investigadas as fontes sociais de aquisição dos saberes dos professores e o grau de mobilização destes de acordo com a fase da carreira profissional. Com relação às fontes dos saberes docentes, a autora aponta: as instituições de formação, as interações sociais entre os docentes, as

3 Três, 19 e 43 anos: período referente aos anos de docência dos colaboradores da pesquisa. 
pesquisas individuais e as experiências acumuladas pela prática docente. Quanto à mobilização dos saberes, a autora percebeu que há uma distinção conforme a fase da carreira em que o docente se encontra. $\mathrm{Na}$ análise dos dados a autora refletiu sobre os aspectos em comum, ou não, entre os grupos de saberes descritos por Tardif e os dados verificados nas entrevistas. Assim, foi reconhecido um grupo de saberes, especificidade deste estudo, o qual a autora nomeou como "saberes da função educativa".

Um grupo formado por diferentes conhecimentos, que o professor de piano adquire, por meios que não se encontram, necessariamente, em sua formação acadêmica de bacharel. Dentre estes conhecimentos cito os processos didático-pedagógicos, o uso de metodologias, os processos motivadores da ação pedagógica, entre outros. Este grupo de saberes, portanto, tem como fonte de aquisição, diferentes possibilidades, que transitam entre os meios experienciais, institucionais e interpessoais. (Araújo, 2005, p. 262).

Na conclusão, assim como na maioria das pesquisas descritas, a autora aponta a necessidade de se repensar os currículos dos cursos de bacharelado em música, com a finalidade de que estes contemplem, além da formação para a performance, a formação docente.

Outro estudo que discute a formação ofertada pelos cursos de bacharelado é a pesquisa de Gemesio (2010), a qual está relacionada à sua formação e posterior experiência como professora de piano. Ao iniciar a carreira docente, a autora vivenciou dificuldades, angústias e sentimentos de incapacidade diante de situações problemáticas das aulas. A autora percebia que mesmo tendo experiências docentes durante sua graduação, sua formação pedagógico-musical era pouca, o que fazia com que seus saberes estivessem fundamentados somente na experiência como aluna e na prática como professora de piano. Após diálogos com colegas de trabalho, que também se encontravam em início de carreira, Gemesio percebeu que seu sentimento de angústia relacionado à prática docente era compartilhado por outros professores iniciantes. Assim, realizou uma pesquisa que teve como objetivo "investigar que saberes os professores de piano, licenciados em educação artística - música, habilitação piano, no início de carreira 
mobilizam na sua prática docente considerando sua história de vida e sua carreira docente" (Gemesio, 2010, p. 13).

A autora realizou a investigação por meio de um estudo de caso com três alunos egressos do curso de Educação Artística - habilitação em Música - Piano da UFU - MG, os quais possuíam até três anos de atuação docente. Os dados para a pesquisa foram coletados a partir de entrevistas semiestruturadas e observações não participantes. Ao analisar os dados, a autora fundamentou-se nos estudos sobre os saberes docentes de Tardif e com relação ao contexto de atuação e inserção dos professores na carreira profissional, nos estudos de Huberman. A partir de categorias que estavam de acordo com temas que surgiram durante as entrevistas (formação musical e formação docente, atuação profissional, saberes mobilizados e início de carreira), a autora percebeu que mesmo os professores colaboradores tendo se formado no mesmo período e na mesma universidade, suas trajetórias profissionais eram distintas. Seus saberes e repertório de conhecimento estão relacionados "ao trabalho que eles exercem, aos espaços de atuação e de certa forma é um repertório de conhecimento em construção vinculado ao contexto de trabalho docente" (Gemesio, 2010, p. 121).

Além disso, a pesquisa apontou algumas dificuldades dos professores em início de carreira, como por exemplo, a necessidade de trabalhar com um repertório que não dominam e a dificuldade de lidar com diferentes alunos (crianças, idosos), visto que a formação acadêmica proporciona pouco contato com esse tipo de situação e com as diferentes faixas etárias. Devido às dificuldades apontadas, os professores sentem a necessidade de ampliar seus conhecimentos e saberes e buscam sanar estas lacunas através da realização de pesquisas, participação em cursos e congressos e até mesmo do retorno à universidade para uma complementação da formação em outro curso. Ao concluir, a autora aponta a necessidade dos cursos proporcionarem alternativas de formação que se enquadrem às necessidades do professor em início de carreira docente e que esta formação acadêmica esteja articulada com os desafios e dificuldades que os egressos dos cursos de música encontrarão no exercício da profissão.

A pesquisa de Weber (2014) partiu da vivência pessoal da autora, bacharel em flauta transversa, a qual atuou como professora de flauta doce e 
transversa desde o período da graduação. As dificuldades encontradas no início da carreira docente foram percebidas como advindas da ausência de uma formação para a docência e do preparo para as situações pedagógicas. Desta forma, a pesquisa buscou compreender o processo de construção da docência de instrumentistas bacharéis que atuam como professores de instrumento, investigando os processos formativos destes profissionais e os saberes que mobilizam na docência do instrumento. a pesquisa, de cunho qualitativo, foi fundamentada no método de investigação biográfico-narrativa (Bolívar; Domingo; Fernandes, 2001), através do qual três colaboradores, bacharéis em instrumento que atuam como professores em espaços não-escolares, foram entrevistados e encorajados a discorrer sobre suas trajetórias formativas e práticas docentes, refletindo sobre o processo de construção do ser professor.

A autora observou que todos os saberes docentes presentes nos referenciais de Tardif e Gauthier são, de uma forma ou outra, mobilizados pelos professores de instrumento. Além disso, identificou um novo saber, específico ao professor de instrumento, o qual nomeou como saber da performance. Tal saber diz respeito aos conhecimentos "relacionados à técnica, expressão musical, comunicação para uma audiência, postura, além do preparo físico e emocional para a apresentação pública" (Weber, 2014, p. 131). Percebendo a relação entre o saber da performance e os saberes disciplinares, a autora identificou sua fonte como relacionadas às disciplinas de instrumento e aos recitais.

A pesquisa apontou ainda que a construção da docência do bacharel em instrumento, ocorre a partir de dois caminhos, para além da formação nas disciplinas ofertadas pelo curso, a socialização com os professores e com os colegas de instrumento e de profissão e da experiência prática com a atividade pedagógica. Os professores de instrumento do bacharelando constituem-se como importantes referenciais sobre o que é ser professor de instrumento. Neste sentido, é natural que participem, através da mobilização do saber da tradição pedagógica, da construção do bacharel enquanto professor. Por outro lado, os saberes experienciais são construídos a partir da reflexão sobre a atividade docente e da busca de soluções para as dificuldades encontradas na prática pedagógica. Para o bacharelando em instrumento, esta prática pode acontecer em 
diferentes espaços, como em escolas particulares, aulas particulares, ou no curso de extensão da própria universidade.

Weber (2014) aponta que não existe uma única forma de se construir professor de instrumento, de modo que o processo de tornar-se docente-bacharel ocorre através da "construção e da mobilização de saberes, os quais são integrados ao ser professor por meio da formação, das vivências junto a professores e colegas, e da experiência com a prática pedagógica" (p. 130). Com base na pesquisa, a autora propõe a necessidade de reflexão sobre os currículos dos cursos de bacharelado em instrumento, reforçando "a necessidade de espaços para a discussão sobre as diferentes possibilidades profissionais do bacharel e de momentos de prática pedagógica orientada durante a graduação" (p. 134).

\section{Considerações finais}

Após refletirmos sobre os saberes docentes necessários ao professor de instrumento e sua articulação com o curso de bacharelado, além de analisarmos as pesquisas em torno da atuação deste professor, alguns pontos em comum ficam visíveis. A totalidade das pesquisas levantadas foi realizada a partir de uma abordagem qualitativa, fundamentando-se, sobretudo, nos estudos de Maurice Tardif, no que tange aos saberes docentes.

Um dos conceitos utilizados em alguns dos estudos mencionados é o de "fases da carreira docente", descrito por Huberman. Segundo Tardif (2012), esse é um importante elemento no estudo desta temática, visto que os saberes dos professores são temporais, ou seja, são saberes que vão sendo adquiridos progressivamente ao longo da realização do trabalho docente. "Uma constatação importante sobressai do nosso material e dos outros diferentes estudos: os saberes dos professores comportam uma forte dimensão temporal, remetendo aos processos através dos quais eles são adquiridos no âmbito de uma carreira no ensino" (Tardif, 2012, p. 82). Neste sentido, nas investigações selecionadas foram estudados professores de piano (bacharéis) em diferentes fases da carreira (Araújo, 
2005) e professores de piano (licenciados em Educação Artística - Habilitação Piano) em início de carreira (Gemesio, 2010).

É necessário refletirmos ainda sobre a estrutura que as instituições formadoras estão oferecendo para preparar este profissional para o mercado de trabalho. Afinal, não podemos continuar mantendo a ideia de que "todo instrumentista é um professor de instrumento". Os músicos bacharéis de fato atuam, quase invariavelmente, como professores, mas a construção desta docência depende, em grande parte, da iniciativa de cada bacharel em procurar espaços para a prática, refletir sobre a adequação de seus modelos, e buscar orientações com colegas ou professores. Algumas universidades incorporam disciplinas de pedagogia do instrumento em seus currículos, embora nem sempre de forma obrigatória. Entretanto, quando existente, muitas vezes esta disciplina é percebida como insuficiente para o preparo do bacharel para a experiência real de ensino do instrumento. Outras oportunidades que podem ser oferecidas pelo curso consistem em espaços de experiência prática orientada, seja na forma de estágio ou em um tipo de laboratório pedagógico, no qual o bacharel possa experienciar a docência em cursos de extensão.

Outro ponto que destacamos diz respeito ao saber da performence, descrito por Weber (2014). É importante salientar que neste trabalho utilizamos o termo "saber da performance" fazendo referência ao professor de instrumento. Porém, a partir da perspectiva das teorias da performance, acreditamos que este saber possa vincular-se a um contexto mais amplo, ou seja, que possa ser mobilizado por professores de outras áreas de conhecimento, pensando-se na performance como relacionada à atuação do professor em sala de aula.

Podemos perceber ainda que a questão da formação oferecida pelos cursos de bacharelado em instrumento é um aspecto recorrente nas conclusões das pesquisas. Neste sentido, a realização desta reflexão e da revisão de literatura possibilitou que confirmássemos a atuação docente do bacharel em instrumento ao mesmo tempo em que percebemos as lacunas formativas do ponto de vista acadêmico. Da mesma forma, pudemos constatar que a construção docente do bacharel se dá por diferentes vias. Assim, destacamos a importância de pesquisas como as descritas neste ensaio, as quais investiguem a formação e a atuação do 
bacharel, de modo que se crie uma base de conhecimentos que subsidiem as discussões e alterações efetivas nas matrizes curriculares dos cursos de bacharelado em instrumento.

\section{Referências}

ARAÚJO, Rosane. Um estudo sobre os saberes que norteiam a prática pedagógica de professores de piano. Tese (Doutorado em Música) - Universidade Federal do Rio Grande do Sul, Porto Alegre, 2005.

. Os saberes docentes na prática pedagógica de professores de piano. Em Pauta, v. 17, n. 28, p. 40-69, 2006.

BELLO, Marcia. Saberes pedagógicos na docência de música. Dissertação (Mestrado em Educação) - Universidade do Vale do Rio dos Sinos, São Leopoldo, 2004.

BOLÍVAR, Antonio; DOMINGO, Jesús; FERNÁNDEZ, Manuel. La investigácion biográfico-narrativa em educación: enfoque e metodologia. Madrid: La muralla, 2001.

BOLZAN, Dóris Pires Vargas. Formação de professores: compartilhando e reconstruindo conhecimentos. Porto alegre: Mediação, 2002.

; ISAIA, Sílvia. Aprendizagem docente na educação superior: construções e tessituras da professoralidade. Revista Educação, n. 3, p. 489-501. Porto Alegre, set./dez. 2006.

BRASIL. Lei No ${ }^{\circ}$ 9394, de 20 de dezembro de 1996. Dispõe sobre as Diretrizes e Bases da Educação Nacional, 1996. 136

CARVALHO, Isamara Alves. Saberes docentes dos instrumentistas professores: diálogo entre ensinar e avaliar um curso de instrumento musical. Dissertação (Mestrado em Educação) - Universidade Federal de São Carlos, São Carlos, 2004.

CLARKE, ERIC. Understanding the psychology of performance. In: RINK, John. Musical performance. p. 59-72, Cambridge: University Press, 2002.

GAUTHIER, Clermont. et al. Por uma teoria da pedagogia: pesquisas contemporâneas sobre o saber docente. Tradução: Francisco Pereira. 2. ed. Ijuí: Ed. Unijuí, 2006.

GEMESIO, Cláudia. "Eu ensino da mesma forma que aprendi": práticas e saberes de três professores de piano em início de carreira, licenciados em educação artística - música, habilitação - piano. Dissertação (Mestrado em Música) Universidade de Brasília, Brasília, 2010.

GLASER, Scheilla R; FONTERRADA, Marisa. Músico-professor: uma questão complexa. Música Hodie, v. 7, n. 1, p. 27-49, 2007. 
ISAIA, Sílvia; BOLZAN, Dóris. Trajetórias da docência: articulando estudos sobre processos formativos e a aprendizagem de ser professor. In: ISAIA, Sílvia; BOLZAN, Dóris (Orgs.). Pedagogia universitária e desenvolvimento profissional docente. $p$. 121-143. Porto Alegre: EDIPUCRS, 2009. 138

; BOLZAN, Dóris. Movimentos construtivos da docência/aprendizagem: tessituras formativas. In: XV ENDIPE, 2010, Belo Horizonte. Anais do XV ENDIPE. Encontro Nacional de didática e prática de ensino. v. 1. p. 1-14, Belo Horizonte: UFMG, 2010 a.

MIZUKAMI, Maria das Graças Nicoletti. Formação continuada e complexidade da docência: o lugar da universidade. In: Encontro Nacional de Didática e Prática de Ensino, 14., 2008, Porto Alegre. Trajetórias e processos de ensinar e aprender: lugares, memórias e culturas. Anais. Porto Alegre: ENDIPE, 2008.

OLIVEIRA, Karla. Professores de piano: um estudo sobre o perfil de formação e atuação em Porto Alegre/RS. Dissertação (Mestrado em Música) - Universidade Federal do Rio Grande do Sul, Porto Alegre, 2007.

OLIVEIRA, Valeska. Processos formativos. In: MOROSINI, Marília C. Enciclopédia de pedagogia universitária: glossário. v. 2, Brasília: Instituto Nacional de Estudos e Pesquisas Educacionais Anísio Teixeira, 2006, p. 352.

PUENTES, Roberto; AQUINO, Orlando; NETO, Armindo. Profissionalização dos professores: conhecimentos, saberes e competências necessários à docência. Educar em Revista, v. 34, p. 169-184, Curitiba, 2009.

RAMOS, Fabiana; CARVALHO, Hágabe; FLEURY, Natalia; SILVA, Carlos. Docência Universitária: a Especificidade da formação didático-pedagógica para o professor bacharel. In: II Simpósio de Docência Universitária da UEG/ESEFFEGO, Goiânia, 2010.

REQUIÃO, Luciana. Saberes e competências no âmbito das escolas de música alternativas: a atividade docente do músico-professor na formação profissional do músico. Revista da Abem, v. 7, p. 59-67, 2002. 140

SANTOS, Ana Roseli. Formação e prática do professor de instrumento de cordas. Dissertação (Mestrado em Educação) - Universidade Estadual de Campinas, Campinas, 2008.

SLOBODA, John A. The musical mind: the cognitive psychology of music. Oxford: Oxford University Press, 1985.

TARDIF, Maurice. Saberes docentes e formação profissional. 13. ed. Petrópolis, RJ: Vozes, 2012.

WEBER, Vanessa. Tornando-se professor de insturmento: narrativas de docentesbacharéis. Dissertação (Mestrado em Educação) - Universidade Federal de Santa Maria, Santa Maria, 2014. 